\title{
HUBUNGAN ANTARA AGRESI RELASIONAL DAN SELF- ESTEEM MAHASISWI UNIVERSITAS X
}

\author{
Erika Harianto ${ }^{1}$, \\ David Matahari, \\ Jessica Ariela \\ Fakultas Psikologi \\ Universitas Pelita Harapan \\ Jl. MH. Thamrin Boulevard, Lippo Karawaci \\ Tangerang 15811, Indonesia \\ 'e-mail: erikaharianto@yahoo.com
}

\begin{abstract}
The present study examines the relationship between relational aggression and self-esteem. Participants of this study were 281 active student of University $X$ aged 18-25 years. Data collection was done by employing online questionnaires. The questionnaires included three measuring instruments that have been adapted to the Indonesian language, which were Rosenberg Self-Esteem Scale, Self-Report of Aggression and Social Behavior Measure, and the Marlowe-Crowne Social desirability Scale Form $C$. The results showed that there is no significant correlation between relational aggression and self-esteem. Other findings related to the research variables are also discussed in the present study.
\end{abstract}

Keywords: relational aggression; proactive relational aggression; reactive relational aggression; self-esteem; early adulthood

\begin{abstract}
Abstrak - Penelitian ini bertujuan untuk menguji hubungan antara agresi relasional dan self-esteem mahasiswi. Partisipan dari penelitian ini terdiri dari 281 mahasiswi aktif Universitas $\mathrm{X}$ yang berusia 18-25 tahun. Peneliti menggunakan kuesioner secara online untuk mengumpulkan data. Kuesioner mencakup tiga alat ukur yang sudah diadaptasi, yaitu Rosenberg Self-Esteem Scale, Self-Report of Aggression and Social Behavior Measure, dan Marlowe-Crowne Social Desirability Scale Form C. Hasil penelitian menunjukkan bahwa tidak adanya korelasi yang signifikan antara agresi relasional dan self-esteem. Penemuan lainnya terkait dengan variabel penelitian juga didiskusikan dalam penelitian ini.
\end{abstract}

Kata Kunci: agresi relasional; agresi relasional proaktif; agresi relasional reaktif; keberhargaan diri; dewasa awal 


\section{PENDAHULUAN}

Pada tahap dewasa awal, individu berfokus untuk menciptakan relasi yang intim dengan orang lain (Papalia \& Feldman, 2012). Dalam sebuah relasi, tetap terdapat potensi agresi. Agresi merupakan tindakan sengaja yang ditujukan kepada orang lain dengan tujuan menyakiti orang tersebut (Kenrick, Neuberg, \& Cialdini, 2007). Perempuan pada umumnya mendemonstrasikan perilaku agresinya dengan agresi relasional (Crothers, Lipinski, \& Minutolo, 2009). Agresi relasional adalah agresi yang dilakukan dengan tujuan untuk merusak hubungan sosial ataupun membahayakan reputasi orang lain (Dailey, Frey, \& Walker, 2015). Oleh karena kecenderungan agresi relasional yang dilakukan perempuan, maka peneliti memilih partisipan berjenis kelamin perempuan dalam penelitian ini.

Fenomena agresi relasional ditemukan pula di Indonesia. Salah satu bentuk dari agresi relasional adalah perundungan siber (Johnson, 2009). Margono, Yi, dan Raikundalia (2014) menyatakan bahwa perundungan siber merupakan pelanggaran terhadap hak asasi manusia yang sengaja dilakukan untuk menyakiti atau mempermalukan orang lain melalui teknologi, seperti internet, telepon genggam, dan sebagainya. Akamai (dalam Margono, Yi, \& Raikundalia, 2015) menyatakan bahwa Indonesia merupakan tempat terjadinya perundungan siber yang terburuk dibandingkan dengan China dan Amerika Serikat. Persentase dari perundungan siber di Indonesia meningkat dari 21 persen hingga 38 persen (Margono dkk., 2015). Hal ini menunjukkan bahwa rentan terjadinya perundungan siber di Indonesia.

Terdapat beberapa kasus yang menunjukkan fenomena agresi relasional yang termanifestasi melalui perundungan siber di Indonesia. Salah satunya adalah seorang mahasiswi yang telah melakukan penghinaan dan pencemaran nama baik terhadap golongan tertentu melalui curhatan di media sosialnya sehingga menimbulkan kebencian atau permusuhan individu (Sucahyo, 2015). Kasus lainnya yang serupa ditemukan pada Melati, seorang mahasiswi yang menjadi korban dari ujaran kebencian di media sosial. Seorang perempuan di salah satu media sosial menyebutkan Melati memiliki permasalahan utangpiutang, padahal Melati menyatakan permasalahan tersebut sudah terselesaikan sebelumnya (Wahyudi, 2015). Ilustrasi tersebut menunjukkan bahwa ujaran kebencian merupakan salah satu bentuk dari agresi relasional yang terjadi akhir-akhir ini.

Peneliti menemukan pula fenomena lainnya di Universitas X. Survei yang dilakukan terhadap 119 mahasiswi Universitas X yang berusia 18-25 tahun pada tahun 2016 menyajikan 
data bahwa 63.9 persen mahasiswi pernah menyebarkan gosip tentang orang lain, sementara 59.7 persen mahasiswi pernah membuat orang lain tidak dilibatkan dalam aktivitas kelompok. Penyebaran gosip dan membuat orang lain tidak dilibatkan dalam aktivitas kelompok merupakan cakupan dari agresi relasional. Berdasarkan penjelasan di atas, dapat disimpulkan bahwa sebagian besar mahasiswi Universitas $\mathrm{X}$ pernah melakukan agresi relasional kepada orang lain. Hal tersebut juga menjadi alasan peneliti memilih mahasiswi Universitas X sebagai partisipan dari penelitian ini.

Agresi relasional dapat memberikan dampak negatif terhadap pelaku agresi. Menurut Goldstein (2011), agresi relasional dapat merusak relasi dan perkembangan individu. Young, Nelson, Hottle, Warburton dan Young (2011) menyatakan bahwa agresi relasional dapat menyebabkan pelaku cenderung mendapatkan penolakan dari kelompok sebayanya. Ketika pelaku sengaja ingin merusak hubungan sosial dengan teman sebayanya, pelaku akan cenderung tidak disukai oleh teman sebayanya dalam jangka waktu yang cukup panjang (Cheng, 2009). Di sisi lain, pada tahap perkembangan dewasa awal, individu berfokus untuk menciptakan relasi yang intim dengan orang lain (Papalia \& Feldman, 2012). Tindakan agresi relasional yang dilakukan oleh pelaku dapat menghambat orang lain untuk mengembangkan relasi harmonis dengan diri pelaku. Hal tersebut berdampak pada kemungkinan terjadinya penolakan dari kelompok teman sebaya terhadap pelaku agresi relasional tersebut. Penolakan tersebut merupakan salah satu faktor yang memengaruhi self-esteem individu (Mruk, 2006). Jika individu mengalami penolakan dari orang-orang di sekitar, maka hal tersebut dapat menurunkan self-esteem individu. Dengan kata lain, self-esteem dari pelaku agresi relasional mungkin saja menurun.

Selain itu, pada pelaku agresi relasional, individu akan mengalami depresi, isolasi sosial, kualitas pertemanan yang lebih buruk, kepuasan hidup yang lebih negatif, ketidakpuasan dengan relasi, ketidakstabilan emosi, terlibat dengan self-destructive behavior, dan maladjustment problem (Young dkk., 2011). Gejala depresi, kecemasan, dan ketidakstabilan emosi yang dialami oleh pelaku dari agresi relasional juga merupakan ciri-ciri yang dapat ditemukan pada individu dengan self-esteem yang rendah (Leary \& MacDonald, dalam Mruk, 2006). Rosenberg (dalam Mruk, 2013) menyatakan bahwa self-esteem merupakan sebuah orientasi positif ataupun negatif terhadap diri sendiri.

Salah satu faktor yang memengaruhi self-esteem adalah kegagalan (Mruk, 2006). Kegagalan tersebut dapat membuat individu merasa putus asa. Adapun salah satu faktor lain yang merupakan faktor yang dapat memengaruhi agresi pada individu adalah rasa putus asa 
(Myers, 2013). Individu yang merasakan rasa putus asa ingin mengeluarkan perasaan marah yang ditahannya sehingga perasaan marah tersebut mungkin saja dikeluarkan melalui perilaku agresi kepada orang lain (Berkowitz, dalam Myers, 2013).

Selain itu, ketika individu memiliki self-esteem yang rendah, individu juga memiliki tingkat toleransi yang rendah terhadap frustrasi (Brown, 2014). Hal tersebut membuat individu menjadi rentan mengalami frustrasi. Di sisi lain, frustrasi tersebut pun dapat memicu rasa marah yang berujung pada perilaku agresi (Myers, 2013). Selain itu, individu yang memiliki self-esteem yang rendah mengalami kecemasan yang berlebihan. Untuk mengurangi kecemasan yang berlebihan, individu dapat kompensasi dengan mengeluarkan rasa marah yang berujung pada agresi relasional (Young, 2007).

Oleh karena semua yang telah dipaparkan sebelumnya, maka peneliti ingin meneliti kaitan antara perilaku agresi relasional dengan self-esteem yang dimiliki oleh mahasiswi Universitas $X$. Hipotesis penelitian ini ialah: ada hubungan yang signifikan antara agresi relasional dan self-esteem mahasiswi Universitas X.

\section{METODE}

\section{Partisipan}

Partisipan dari penelitian ini terdiri dari 281 mahasiswi Universitas X berusia 18-25 tahun. Adapun teknik sampling yang dipilih oleh peneliti adalah non-probability sampling. Dalam non-probability sampling, setiap individu dalam populasi tidak memiliki peluang yang sama untuk dipilih menjadi sampel (Gravetter \& Forzano, 2012). Jenis non-probability sampling yang akan dilakukan dalam penelitian ini adalah purposive sampling. Dengan teknik sampling ini, peneliti akan mengumpulkan data sesuai dengan kriteria partisipan yang telah ditentukan oleh peneliti. Peneliti menggunakan kuesioner online (surveymonkey) untuk mengumpulkan data dari partisipan.

\section{Desain}

Desain penelitian yang digunakan oleh peneliti pada penelitian ini adalah metode penelitian kuantitatif dengan pengujian korelasional. 


\section{Instrumen}

Peneliti melakukan adaptasi tiga alat ukur baku. Pertama, yaitu Rosenberg Self-Esteem Scale yang dikembangkan oleh Rosenberg (1979) untuk mengukur self-esteem. Alat ukur ini terdiri dari 10 butir dengan 5 butir yang menunjukkan penilaian positif terhadap diri sendiri dan 5 butir yang menunjukkan penilaian negatif terhadap diri sendiri. Adapun skala yang digunakan dalam alat ukur Rosenberg Self-Esteem Scale (RSES) merupakan skala Likert dengan rentang 1 sampai 4, yaitu sangat tidak setuju, tidak setuju, setuju, dan sangat setuju. Perhitungan skor dilakukan dengan cara menjumlahkan skor butir penilaian negatif yang sudah di-reverse dengan skor penilaian positif partisipan.

Sebelum alat ukur ini disebarkan ke partisipan, peneliti melakukan uji coba alat ukur Rosenberg Self-Esteem Scale (RSES) terlebih dahulu kepada 44 mahasiswi Universitas X. Hasil uji coba menunjukkan bahwa alat ukur ini memiliki reliabilitas di atas standar, yaitu dengan koefisien Cronbach's alpha .84. Adapun standar reliabilitas yang digunakan dalam penelitian ini adalah $\alpha \geq .70$ (Guildford \& Fruchter, dalam Gregory, 2007). Namun, terdapat 1 butir alat ukur yang memiliki Corrected Item-Total Correlation di bawah .20 sehingga peneliti mengeliminasi butir tersebut, yaitu butir nomor delapan. Setelah dihapus, reliabilitas koefisien Cronbach's alpha pun meningkat menjadi .85 dengan total nomor sebanyak 9 butir.

Kedua, peneliti menggunakan Self-Report of Aggression and Social Behavior Measure yang dikembangkan oleh Morales dan Crick (dalam Linder, Crick, \& Collins, 2002) untuk mengukur agresi relasional. Skala yang digunakan dalam alat ukur Self-Report of Aggression and Social Behavior Measure (SRASBM) merupakan skala Likert dengan rentang 1 sampai 7, yaitu 1 menandakan sangat tidak setuju dan 7 menandakan sangat setuju. Alat ukur ini terdiri dari 56 butir dengan jumlah total 11 butir pernyataan yang mengukur agresi relasional. Adapun 11 butir tersebut mencakup 5 butir yang mengukur agresi relasional proaktif dan 6 butir sisanya yang mengukur agresi relasional reaktif, sedangkan 45 butir lainnya mengukur variabel lainnya, seperti agresi fisik, eksklusifitas, perilaku prososial, relational victimization, dan physical victimization sehingga peneliti hanya menggunakan butir-butir yang mengukur agresi relasional. Perhitungan skor agresi relasional dilakukan dengan menjumlahkan skor agresi relasional proaktif dan reaktif.

Hasil uji coba menunjukkan bahwa alat ukur ini memiliki reliabilitas yang di atas standar, yaitu dengan koefisien Cronbach's alpha .78. Namun, ada 1 butir alat ukur yang memiliki Corrected Item-Total Correlation di bawah .20 sehingga peneliti mengeliminasi 
butir tersebut, yaitu butir nomor lima. Setelah dihapus, reliabilitas koefisien Cronbach's alpha pun meningkat menjadi .79 dengan total nomor sebanyak 10 butir.

Ketiga, peneliti menggunakan Marlowe-Crowne Social Desirability Scale Form C dengan versi pendek sebanyak 13 butir yang dikembangkan oleh Reynolds (1982) untuk mengukur social desirability dengan jawaban benar atau salah. Menurut Reynolds (1982), Marlowe-Crowne Social Desirability Scale Form C merupakan bentuk alat ukur versi pendek yang paling kuat secara psikometri dengan reliabilitas sebesar .76. Skor untuk jawaban benar adalah 1, sedangkan skor untuk jawaban salah adalah 2. Perhitungan skor dilakukan dengan melakukan proses reverse skor butir unfavorable, kemudian dijumlahkan dengan butir favorable.

Hanya saja, setelah peneliti melakukan uji coba alat ukur tersebut, reliabilitas yang diperoleh di bawah standar, yaitu dengan koefisien Cronbach's alpha .55. Dengan reliabilitas seperti itu, ada beberapa butir yang memiliki Corrected Item-Total Correlation di bawah .20 sehingga peneliti mengeliminasi butir tersebut satu per-satu sampai mendapatkan Corrected Item-Total Correlation di atas .20. Butir-butir yang dihapus yaitu nomor sebelas, enam, satu, empat, tiga, dan dua. Setelah dihapus, reliabilitas koefisien Cronbach's alpha pun meningkat menjadi .67 dengan total nomor sebanyak 7 butir.

Adapun untuk menambahkan kontrol variabel, peneliti menambahkan variabel penolakan yang akan diukur. Peneliti pun menggunakan satu pernyataan yang dibuat untuk mengukur penolakan, yaitu "Saya merasa mendapatkan penolakan dari orang-orang sekitar saya." Dengan kata lain, pernyataan tersebut menunjukkan bahwa yang diukur merupakan persepsi individu terhadap penolakan yang ada. Pernyataan tersebut digabungkan dengan alat ukur Rosenberg Self-Esteem Scale sehingga skala yang digunakan merupakan skala Likert dengan rentang 1 sampai 4, yaitu sangat tidak setuju, tidak setuju, setuju, dan sangat setuju.

\section{Prosedur}

Peneliti menggunakan mobile survey dengan media sosial berupa aplikasi Line melalui percakapan personal untuk menyebarkan tautan kuesioner sehingga partisipan dapat mengakses tautan tersebut. Peneliti tidak menyebarkan tautan kuesioner tersebut di halaman utama dari aplikasi sehingga kuesioner tidak tersebar ke mahasiswa/i universitas lain untuk meminimalisir kesalahan yang terjadi, misalnya partisipan dari universitas lain mengisi kuesioner tersebut. Dalam penyebaran data, peneliti pun menekankan bahwa partisipan yang 
mengisi kuesioner ini adalah mahasiswi Universitas $\mathrm{X}$ dengan memberikan tambahan keterangan seperti "WOMAN ONLY" pada penjelasan singkat mengenai tautan kuesioner tersebut. Hal ini bertujuan supaya calon partisipan benar-benar sadar dan mengetahui bahwa kuesioner ini diperuntukkan untuk mahasiswi saja sehingga meminimalisir kesalahan yang mungkin terjadi, misalnya ternyata ada mahasiswa laki-laki yang mengisi kuesioner tersebut.

Selain itu, di lembar informed consent, peneliti memastikan lagi dengan menyediakan pilihan jenis kelamin sehingga partisipan yang mengisi dapat memilih pilihan tersebut. Jika ia memilih perempuan, maka ia dapat lanjut ke lembar berikutnya. Namun, jika ia memilih lakilaki, maka ia langsung mengakhiri survei tersebut dan tidak dapat mengambil bagian dalam mengisi kuesioner lagi. Dari total 418 partisipan yang mengisi kuesioner, hanya 281 data yang dapat digunakan dalam penelitian ini. Sisa data lainnya tidak dapat digunakan karena ketidaksesuaian usia dan jenis kelamin, serta ketidaklengkapan dalam pengisian kuesioner.

\section{Teknik Analisis}

Untuk mengetahui normal atau tidaknya persebaran data yang diperoleh, peneliti menggunakan uji normalitas Kolmogorov-Smirnov. Data yang diperoleh tidak berada pada kurva distribusi normal sehingga peneliti menggunakan uji non-parametrik dengan korelasi Spearman's Rho.

\section{ANALISIS DAN HASIL}

Hasil dari uji normalitas variabel self-esteem dan agresi relasional menunjukkan hasil dimana variabel tersebut memiliki distribusi data yang tidak normal $(p=.000)$, sehingga pengolahan data yang digunakan adalah uji non-parametrik. Berikut merupakan tabel yang merangkum gambaran agresi relasional, self-esteem, serta persepsi penolakan partisipan. 
Tabel 1.

Analisis Deskriptif Variabel

\begin{tabular}{llllllll}
\hline Variabel & Subtipe & $\boldsymbol{N}$ & $\begin{array}{l}\text { Jumlah } \\
\text { Butir }\end{array}$ & Min & Max & $\boldsymbol{M}$ & SD \\
\hline Agresi & Proaktif & 281 & 4 & 4 & 24 & 7.62 & 3.64 \\
Relasional & Reaktif & 281 & 6 & 6 & 33 & 13.6 & 5.03 \\
& Total & 281 & 10 & 10 & 57 & 21.22 & 7.99 \\
Self-Esteem & - & 281 & 9 & 9 & 36 & 25.66 & 3.79 \\
$\begin{array}{l}\text { Persepsi } \\
\text { Penolakan }\end{array}$ & - & 281 & 1 & 1 & 4 & 2.16 & 0.74 \\
$\begin{array}{l}\text { Social } \\
\text { Desirability }\end{array}$ & - & 281 & 7 & 7 & 14 & 11.6 & 1.612 \\
\hline
\end{tabular}

Nilai mean agresi relasional proaktif sebesar 7.62 dengan nilai minimum 4 dan nilai maksimum 24. Selain itu, nilai mean agresi relasional reaktif sebesar 13.6 dengan nilai minimum 6 dan nilai maksimum 33. Hal ini menunjukkan bahwa rata-rata skor agresi relasional proaktif dan reaktif yang diperoleh partisipan cenderung rendah dikarenakan skor rata-rata mendekati nilai minimum. Dengan kata lain, partisipan cenderung tidak melakukan agresi relasional baik secara proaktif maupun reaktif.

Nilai mean dari variabel self-esteem adalah 25.66 dengan nilai minimum 9 dan nilai maksimum 36. Hal ini menunjukkan bahwa partisipan dari penelitian ini memiliki self-esteem yang cenderung tinggi karena rata-rata skor self-esteem yang diperoleh mendekati nilai maksimum. Adapun nilai mean dari persepsi penolakan adalah sebesar 2.16 dengan nilai minimum 1 dan nilai maksimum 4. Hal ini menunjukkan bahwa cukup banyak partisipan dari penelitian ini yang merasa mendapatkan penolakan dari orang-orang sekitarnya.

Nilai minimum variabel social desirability adalah 7, sedangkan nilai maksimum dari alat ukur ini adalah 14. Mean yang didapatkan dari alat ukur ini sebesar 11.6 dengan standar deviasi 1.612. Nilai mean tersebut mendekati nilai maksimum yang ada. Hal ini menunjukkan bahwa kecenderungan faking good dari partisipan diduga tinggi.

Hasil olah data menunjukkan bahwa tidak ada korelasi yang signifikan antara perilaku agresi relasional dan self-esteem mahasiswi Universitas $\mathrm{X}\left(r_{s}=-.103 ; p=.085\right)$. Dengan begitu, $H_{0}$ diterima, yaitu tidak ada hubungan yang signifikan antara perilaku agresi relasional dengan self-esteem mahasiswi. Selain itu, ditemukan juga korelasi yang signifikan antara persepsi partisipan terhadap penolakan dengan agresi relasional $\left(r_{s}=.243 ; p=.000\right)$ dan self-esteem $\left(r_{s}=-.470 ; p=.000\right)$. 
Peneliti juga menganalisis data berdasarkan subtipe agresi relasional. Hasil menunjukkan bahwa tidak ditemukan korelasi yang signifikan antara self-esteem dengan agresi relasional proaktif $\left(r_{s}=-.033 ; p=.586\right)$. Namun, ditemukan korelasi yang signifikan antara self-esteem dengan agresi relasional reaktif $\left(r_{s}=-.131 ; p=.029\right)$. Peneliti juga melakukan uji korelasi antara agresi relasional dengan total skor dari alat ukur MarloweCrowne Social Desirability Short Form C. Hasilnya menunjukkan bahwa ada korelasi yang signifikan antara agresi relasional dengan total skor alat ukur tersebut $\left(r_{s}=-.314, p=.000\right)$. Berikut merupakan tabel yang merangkum hasil uji korelasi:

Tabel 2.

Rangkuman Uji Korelasi Spearman

\begin{tabular}{lll}
\hline Variabel & Koefisien Korelasi $\left(\boldsymbol{r}_{\boldsymbol{s}}\right)$ & Nilai Signifikansi $(\boldsymbol{p})$ \\
\hline Agresi relasional dan self-esteem & -.103 & .085 \\
Agresi relasional dan persepsi penolakan & .243 & $.000^{* *}$ \\
Persepsi penolakan dan self-esteem & -.470 & $.000^{* *}$ \\
Agresi relasional proaktif dan self-esteem & -.033 & .586 \\
Agresi relasional reaktif dan self-esteem & -.131 & $.029 *$ \\
\hline Ket $*$ Korelasi signifikan pada $p<.05 * * *$ Korelasi signifikan pada $p<.01$ &
\end{tabular}

Ket.: *. Korelasi signifikan pada $p<.05 ; * *$ Korelasi signifikan pada $p<.01$

\section{DISKUSI}

Penelitian menunjukkan bahwa tidak ada hubungan yang signifikan antara perilaku agresi relasional dengan self-esteem mahasiswi. Peneliti memberikan tiga argumentasi mengenai hasil penelitian ini. Pertama, yaitu tugas perkembangan dewasa awal yang tidak hanya berfokus pada relasi, melainkan juga ada pekerjaan serta cara pandang mengenai dunia yang dapat dibentuk melalui pendidikan (Arnett, 2000). Hal ini membuat self-esteem individu tidak hanya bersumber dari relasi saja, tetapi juga pekerjaan dan cara pandang.

Kedua, korelasi yang tidak signifikan juga diduga berkaitan dengan efek kegagalan yang berbeda pada setiap individu. Ketika individu merasa gagal, maka ia mungkin saja merasa putus asa. Adapun keputus-asaan merupakan salah satu faktor yang memengaruhi individu untuk melakukan agresi (Myers, 2013). Hanya saja, tidak selalu individu akan merasa putus asa sehingga menyebabkan adanya perilaku agresi. Mungkin saja individu melakukan refleksi terhadap kegagalan yang dialaminya dan membandingkan dirinya dengan orang lain yang mengalami hal yang lebih buruk darinya sehingga self-esteem individu pun dapat meningkat tanpa adanya perilaku agresi (Eysenck, 2004). Selain itu, menurut self- 
affirmation theory, individu juga dapat mengkompensasi kegagalan tersebut dengan melihat kualitas positif dalam diri pada aspek lain yang ada di dalam dirinya (Myers, 2013).

Ketiga, korelasi antara agresi relasional dan self-esteem yang tidak signifikan juga diduga berkaitan dengan kemungkinan faking good yang dilakukan oleh partisipan. Adapun rata-rata skor alat ukur social desirability yang didapatkan dari partisipan penelitian ini adalah 11.6 dengan rentang nilai minimum 7 dan nilai maksimum 14. Hal ini menunjukkan bahwa jika dibandingkan dengan nilai minimum dan maksimum skor, maka rata-rata skor yang ada tergolong cukup tinggi karena mendekati nilai skor maksimum, yaitu 14.

Hasil juga menunjukkan bahwa adanya korelasi yang signifikan antara persepsi penolakan dengan agresi relasional. Hal ini sesuai dengan teori Young dkk. (2011) yang menyatakan bahwa individu yang melakukan agresi relasional cenderung mendapatkan penolakan dari kelompoknya. Interpretasi arah yang berbeda juga dapat terjadi, yaitu penolakan tersebut justru juga dapat dianggap sebagai serangan oleh beberapa orang dan dapat menyebabkan rasa sakit yang berujung frustrasi sehingga memicu individu untuk melakukan agresi kepada orang lain (Fiske, Gilbert, \& Lindzey, 2010).

Selain itu, ditemukan korelasi yang signifikan antara persepsi penolakan dan selfesteem. Hal ini sesuai dengan teori Epstein (dalam Mruk, 2006) yang menyatakan bahwa penolakan tersebut merupakan salah satu faktor yang dapat menurunkan self-esteem individu. Ketika individu merasa bahwa dirinya ditolak oleh orang lain, maka individu akan cenderung merasa bahwa dirinya tidak berharga sehingga membuat self-esteem individu menurun. Sebaliknya, semakin individu memiliki self-esteem yang rendah, maka semakin tinggi penolakan yang dapat ia persepsikan. Menurut Epstein (dalam Brown, 2014), hal ini dapat disebabkan karena individu dengan self-esteem yang rendah cenderung sensitif terhadap penolakan atau memiliki rejection sensitivity yang tinggi sehingga dapat menurunkan selfesteem individu.

Hasil olah data juga menunjukkan bahwa tidak ditemukan korelasi yang signifikan antara self-esteem dengan agresi relasional proaktif $\left(r_{s}=-.033 ; p=.586\right)$. Hal ini diduga disebabkan karena adanya faktor lain yang memengaruhi korelasi ini yaitu, narsisisme. Narsisisme yang ada dalam individu dapat membuat individu cenderung melakukan agresi hanya untuk tujuan lain. Dengan kata lain, individu akan cenderung melakukan agresi relasional proaktif yang bersifat instrumental, misalnya untuk mendapatkan status ataupun atensi dari orang lain (Barry dkk., 2007). 
Hanya saja, ditemukan korelasi yang signifikan antara self-esteem dengan agresi relasional reaktif $\left(r_{s}=-.131 ; p=.029\right)$. Korelasi negatif yang signifikan ini diduga dapat disebabkan karena individu dengan self-esteem yang rendah memiliki tingkat toleransi yang rendah terhadap frustrasi sehingga individu rentan mengalami frustrasi (Brown, 2014). Adapun frustrasi merupakan hal-hal yang memblokir individu untuk mencapai goal yang dimilikinya (Myers, 2013).

Berdasarkan teori frustration-aggression, frustrasi akan memicu rasa marah yang menjadi tanda sebagai kesiapan untuk melakukan agresi (Myers, 2013). Dengan begitu, rasa marah tersebut dapat membuat individu melakukan agresi relasional reaktif yang merupakan respon yang defensif terhadap frustrasi yang dialaminya. Jadi, semakin rendah self-esteem, maka semakin tinggi potensi agresi relasional reaktif yang ada. Hal tersebut lah yang membuat adanya korelasi negatif yang signifikan antara agresi relasional reaktif dan selfesteem.

Hasil olah data tambahan juga menunjukkan bahwa ada korelasi yang signifikan antara agresi relasional dengan total skor alat ukur social desirability. Hal ini disebabkan karena partisipan dari penelitian ini merupakan masyarakat Indonesia yang, menurut Hofstede (2016), tergolong memiliki budaya kolektivisme. Penelitian dari Lalwani, Shavitt, dan Johnson (2006) juga menemukan bahwa budaya kolektivisme cenderung merespon secara socially desirable untuk mempertahankan relasi yang baik dan diterima oleh dengan orang lain sehingga tingkat social desirability individu pun tinggi.

\section{SIMPULAN DAN SARAN}

\section{Simpulan}

Secara singkat, hasil dari penelitian dapat dijabarkan ke dalam dua bagian, yaitu kesimpulan hasil uji hipotesis dan kesimpulan hasil analisis data tambahan. Dari kesimpulan hasil uji hipotesis, tidak ada korelasi yang signifikan antara agresi relasional dan self-esteem. Hal ini disebabkan karena adanya tugas perkembangan individu yang tidak hanya berfokus pada relasi, efek kegagalan yang berbeda pada setiap individu, dan kecenderungan faking good individu. Hanya saja, jika persepsi individu terhadap penolakan diperhitungkan sebagai variabel yang berada di antara agresi relasional dan self-esteem, maka ditemukan korelasi yang signifikan antara penolakan dengan agresi relasional dan self-esteem. 
Selain itu, juga ditemukan korelasi negatif yang signifikan antara agresi relasional reaktif dengan self-esteem. Korelasi yang signifikan mungkin saja disebabkan karena individu dengan self-esteem yang rendah memiliki toleransi yang rendah terhadap frustrasi sehingga dapat berujung pada agresi relasional secara reaktif. Namun, tidak ditemukan korelasi yang signifikan antara agresi relasional proaktif dengan self-esteem yang mungkin saja disebabkan karena adanya faktor lain, yaitu narsisisme.

\section{Saran Teoretis}

Peneliti menyarankan beberapa saran teoretis untuk penelitian ke depannya. Pertama, sebaiknya peneliti yang selanjutnya ingin melakukan penelitian mengenai self-esteem memperhitungkan variabel-variabel lain yang mungkin saja memengaruhi self-esteem, seperti narsisisme yang mungkin saja membuat self-esteem menjadi tinggi dan menimbulkan kecenderungan agresi. Kedua, peneliti menyarankan bagi para peneliti selanjutnya yang ingin menambahkan kontrol variabel, contohnya persepsi penolakan, maka ada baiknya untuk menggunakan alat ukur variabel yang benar-benar terstandarisasi dan memiliki validitas serta reliabilitas yang baik. Ketiga, peneliti menyarankan untuk menggunakan peer-nomination juga untuk mengukur agresi relasional agar menghindari faking good yang mungkin dilakukan partisipan melalui self-report dan membuat pengukuran lebih objektif.

Keempat, peneliti juga menyarankan untuk menggunakan sociogram analysis agar mengetahui dinamika relasi sosial yang dimiliki individu secara lebih mendalam. Kelima, untuk ke depannya, penelitian agresi relasional yang akan dilaksanakan pada partisipan dengan budaya kolektivisme disarankan untuk menggunakan alat ukur social desirability yang memiliki reliabilitas dan Corrected-Item Total Correlation yang baik sehingga dapat mendeteksi kecenderungan faking good individu. Keenam, penelitian selanjutnya menggunakan self-esteem sebagai prediktor jika ingin dikaitkan dengan agresi relasional reaktif secara langsung. Ketujuh, penelitian selanjutnya disarankan untuk memperluas populasi dan sampel sehingga generalisasi tidak hanya terbatas pada mahasiswi Universitas X saja. Kedelapan, penelitian selanjutnya juga disarankan untuk melihat self-esteem secara lebih spesifik dalam konteks relasi agar pembahasan dinamikanya terfokus dalam relasi dan kaitannya dengan agresi relasional. 


\section{Saran Praktis}

Secara praktis, penelitian ini memberikan sebuah masukan bagaimana cara untuk menghadapi pelaku agresi relasional. Dalam menghadapi pelaku agresi relasional, individu justru sebaiknya menghadapinya dengan penerimaan. Hal ini disebabkan karena penolakan dapat meningkatkan agresi relasional individu. Adapun penerimaan yang dimaksud adalah penerimaan terhadap keberadaan diri individu, namun bukan berarti penerimaan tersebut berlaku pada perilaku agresi yang dilakukannya.

Selain itu, penelitian ini juga menyarankan kepada masyarakat umum maupun institusi pendidikan untuk dapat mengembangkan self-esteem mahasiswi dengan mengajarkan individu untuk mulai menghargai dirinya sendiri sehingga individu diajarkan untuk dapat melihat kualitas positif yang ada di dalam dirinya dengan berbagai metode, seperti poster ataupun penyuluhan. Tidak hanya itu, guru, guru pembimbing, ataupun dosen yang berada di institusi pendidikan juga disarankan untuk peka dengan lingkungan sosial yang ada di sekolah atau universitas, terutama mengenai hal-hal yang berkaitan dengan self-esteem dan agresi relasional. Hal tersebut dapat dilakukan dengan cara-cara memberikan peraturan tegas terhadap perilaku agresi relasional dan memberikan apresiasi kepada pencapaian murid atau mahasiswi. Selain itu, guru pembimbing juga disarankan untuk lebih aktif untuk bersosialisasi dengan murid atau mahasiswi agar mengetahui dinamika relasi murid atau mahasiswi sehingga guru pembimbing dapat memberikan konsultasi lebih lanjut jika terdapat masalah mengenai self-esteem atau adanya indikasi perilaku agresi relasional.

\section{REFERENSI}

Arnett, J. J. (2000). Emerging adulthood: A theory of development from the late teens through the twenties. American Psychologist, 55(5), 469.

Barry, T. D., Thompson, A., Barry, C. T., Lochman, J. E., Adler, K., \& Hill, K. (2007). The importance of narcissism in predicting proactive and reactive aggression in moderately to highly aggressive children. Aggressive Behavior, 33(3), 185-197.

Brown, J. (2014). The self. New York, NY: Psychology Press.

Cheng, C. L. (2009). No blood means less harm?: Relational aggression and peer rejection in adolescence. Bulletin of Educational Psychology, 40(3), 511-528. 
Crothers, L. M., Lipinski, J., \& Minutolo, M. C. (2009). Cliques, rumors, and gossip by the water cooler: Female bullying in the workplace. Psychologist-Manager Journal, 12(2), 97-110. doi:10.1080/10887150902886423

Dailey, A. L., Frey, A. J., \& Walker, H. M. (2015). Relational aggression in school settings: Definition, development, strategies, and implications. Children \& Schools, 37(2), 7988. doi:10.1093/cs/cdv003

Eysenck, M. W. (2004). Psychology: An international perspective. New York, NY: Taylor \& Francis.

Fiske, S. T., Gilbert, D. T., \& Lindzey, G. (2010). Handbook of social psychology. Hoboken, NJ: John Wiley \& Sons.

Goldstein, S. E. (2011). Relational aggression in young adults' friendships and romantic relationships. Personal Relationships, 18(4), 645-656. doi: 10.1111/j.14756811.2010.01329.

Gravetter, F. J., \& Forzano, L. (2012). Research methods for the behavioral sciences (4th ed.) Belmont, CA: Wadsworth.

Gregory, R. J. (2007). Psychological testing (5th ed.). Boston, MA: Pearson.

Hofstede, G. (2016). Indonesia - Geert Hofstede. Ditemu kembali dari https://geerthofstede.com/indonesia.html

Johnson, J. M. (2009). The impact of cyber bullying: A new type of relational aggression, American Counseling Association Annual Conference and Exposition, 19-23 Maret 2009, Charlotte, NC. Alexandria, VA: American Counseling Association.

Kenrick, D. T., Neuberg, S. L., Cialdini, R. B. (2007). Social psychology: Goals in interaction (4th ed.). Boston, MA: Allyn and Bacon.

Lalwani, A. K., Shavitt, S., \& Johnson, T. (2006). What is the relation between cultural orientation and socially desirable responding? Journal of Personality and Social Psychology, 90(1), 165.

Linder, J. R., Crick, N. R., \& Collins, W. A. (2002). Relational aggression and victimization in young adults' romantic relationships: Associations with perceptions of parent, peer, and romantic relationship quality. Social Development, 11(1), 71-86.

Margono, H., Yi, X., \& Raikundalia, G. K. (2014). Mining Indonesian cyber bullying patterns in social networks. Proceedings of the Thirty-Seventh Australasian Computer Science Conference-Volume 147 (pp. 115-124). Australian Computer Society. 
Margono, H., Yi, X., \& Raikundalia, G. K. (2015). Clustering Indonesian cyberbullying words in social networks. International Journal of Computer Science and Electronics Engineering, 3(4), 275-278.

Mruk, C. J. (2006). Self-Esteem research, theory, and practice: Toward a positive psychology of self-esteem (3rd ed.). New York, NY: Springer.

Mruk, C. J. (2013). Self-esteem and positive psychology: Research, theory, and practice (4th ed.). New York, NY: Springer.

Myers, D. (2013). Social psychology (11th ed.). New York, NY: McGraw-Hill.

Papalia, D. E., \& Feldman, R. D. (2012). Experience human development (12th ed). New York, NY: McGraw-Hill.

Reynolds, W. M. (1982). Development of reliable and valid short forms of the Marlowe-Crowne Social Desirability Scale. Journal of Clinical Psychology, 38(1), 119125.

Rosenberg, M. (1979). Conceiving the self. New York, NY: Basic Books.

Sucahyo, N. (2015). Menghina melalui media sosial, mahasiswi UGM divonis 2 bulan penjara. Ditemu kembal dari http://www.voaindonesia.com/a/menghina-melaluimedia-sosial-mahasiswi-ugm-divonis-2-bulan-penjara/2701021.html

Wahyudi, M. (2015). Mahasiswi berhijab ini laporkan hate speech ke polisi. Ditemu kembali dari https://sulsel.pojoksatu.id/read/2015/11/27/mahasiswi-berhijab-ini-laporkan-hatespeech-ke-polisi/

Young, T. R. (2007). The relationship between appearance schemas, self-esteem, and indirect aggression among college women (Disertasi doktoral). Ditemu kembali dari UMI Database (UMI no. 3291435).

Young, E. L., Nelson, D. A., Hottle, A. B., Warburton, B., \& Young, B. K. (2011). Relational Aggression among Students. Education Digest: Essential Readings Condensed for Quick Review, 76(7), 24-29. 